expected of treatment with the anti-haemophilia coagulation globulin when it becomes freely available.

The treatment of the haemophilic patient, therefore, can be summarized as (a) protection from and prevention of injury and mechanical strain to joints ; $(b)$ prompt treatment of emergencies in hospital with full haematological control ; $(c)$ avoidance of surgical measures except in cases of great urgency; (d) the close co-operation of physician and dentist or surgeon; and $(e)$ suitable education, rehabilitation, and employment.

\section{Laryngismus Stridulus}

Q.-What are the most modern views on the aetiology and treatment of laryngismus stridulus? I understand that at necropsy no signs of asphyxia are found, and the cause of death is shock. What is the best treatment? Is tracheotomy indicated?

A.- Views on this subject have not undergone any particular revision in recent times. Laryngismus stridulus is essentially a manifestation of tetany and occurs in those cases of rickets with a lowering of the blood calcium (this is over-simplifying the situation). Since rickets has become so rare and even minor forms are unusual in many centres, the laryngeal involvement is very seldom seen to-day. The immediate treatment of tickling the fauces or splashing cold water over the head and face is moderately efficient. Sedatives should then be given at once-for example, chloral and bromide by the rectum or intramuscular soluble phenobarbitone. Large doses of vitamin D are also given by mouth or by injection and will slowly correct the fundamental disorder. Parathormone has been used but is not really necessary in the infantile type of case. The condition can be fatal, as the question indicates, and, if the immediate treatment mentioned is not at once effective, tracheotomy would certainly be justified. Other causes of nervous spasm of the larynx may perhaps be in the questioner's mind, especially the curious phenomena of breathholding or crowing. These, however, are rarely if ever fatal, and for the former the cold-water treatment is usually effective.

\section{Gowers's Syndrome}

Q.-In a recent article in the "British Medical Journal" (February 11, 1950, p. 331) a short description of Gowers's syndrome was given. I have a patient who has on at least two occasions had a typical attack of this condition. I should like to know what precipitates an attack, and how an actual attack may be treated, together with prophylactic measures for avoiding further recurrence. The patient, a man aged 47, has a normal electrocardiograph, normal cholecystograph, and no radiological signs of peptic ulcer. He states that both his attacks occurred shortly after a meal.

A.- Not a great deal is known about the aetiology of the syndrome described by Gowers in his book, The Borderland of Epilepsy (London, 1907), and the diagnosis is often difficult, particularly if through force of circumstances the attack itself is not witnessed by the doctor. Observations on these attacks were made by Ryle (British Medical Journal, 1934, 1, 89). In this and other papers he has rightly emphasized that the most striking, urgent, and dreaded of the symptoms is a sense of impending death. Arising sometimes unexpectedly, but often after a period of prolonged mental strain or anxiety, the attack is usually sudden in onset and may last for ten minutes or half an hour or more before the symptoms begin to abate. The patient will complain of a sense of utter powerlessness, profound weakness, often a sense of unreality in the environment, a sinking or floating feeling, and occasionally also of some minor degree of precordial discomfort, sometimes distinct dyspnoea, a sensation of choking, and perhaps a tingling in the extremities. Facial pallor, cold perspiration, and a superficial appearance of grave illness are at once evident. The pulse is generally slow and of poor volume, but few accurate records of blood pressure, pulse rate, and the response to drugs are available, so that the exact mechanism and its causation are obscure.

The attack is not a hysterical phenomenon, though it is often vaguely labelled "nerves" or confusedly designated a "heart attack." Apparently these attacks, though alarming in themselves and in certain of their features similar to the milder attacks of insulin hypoglycaemia, are never fatal. Whatever the precise mechanism, reassurance as regards the future, combined with sedative drugs, such as small doses of phenobarbitone, do much to diminish their frequency. For the attack itself bromides or phenobarbitone appear equally useful. The investigations undertaken in the particular patient who is the subject of this inquiry might suggest that this man had predominantly dyspeptic symptoms, particularly as his two attacks are said to have occurred shortly after a meal. This is not a usual association of a true attack of Gowers's syndrome, and it would be useful, before making a firm diagnosis, to know more about his symptoms, and in particular about the nature of his supposed dyspepsia.

\section{Intra-articular Injections for Arthritis}

Q.- Some time ago local intra-synovial injections were being advocated for certain cases of arthritis. Can you advise me about (a) the results obtained; (b) the technique, say, for the knee-joint; (c) the type of case, if any, likely to benefit; and (d) the best mixture to use?

A.- In recent years intra-articular injections, usually of an acid solution, have been advocated for certain types of arthritis, mainly those of a degenerative nature (osteoarthritis). The type of case usually considered suitable is one with osteoarthritis of one or more of the major weight-bearing joints, particularly when the disability is not sufficient to demand operative treatment or when the general condition of the patient makes operation inadvisable. The solution most commonly used is lactic acid ( $p \mathrm{H} 5.8)$ or acid potassium phosphate (1\%). There is a proprietary preparation of the latter with $0.5 \%$ procaine added. About 10 to $20 \mathrm{ml}$. of the solution is injected into the joint after local infiltration of the skin and synovial membrane with $2 \%$ procaine. . Six to twelve weekly injections are given. Although significant successes have been claimed the efficacy of this method of treatment still lacks convincing proof. The opinion of the writer, who has made a fairly extensive trial of the method, is that its theoretical basis is unsound and that in practice it is of no value except perhaps as a placebo. It seems probable that many supposed successes have been due to other factors, such as increased periods of rest during the course of the treatment, and suggestion.

\section{NOTES AND COMMENTS}

Survival of the Flea.-Dr. Hugh S. Stannus (London, W.1.) writes : Dr. Adair Girby's comment (April 15, p. 918) on the sudden appearance of large numbers of fleas remarked by Dr. G. C. Adeney (February 18, p. 448), made as if he were stating facts, cannot be allowed to pass without correction. He appears to be ignorant of the life history of the flea. The egg after two to four days hatches out the larva, which feeds on dead organic matter and undergoes three moults, as a rule three to four, five to six, and seven to fourteen days after hatching. The larva then spins a cocoon in which the pupa becomes imago in about five days. The life history from egg to adult flea therefore takes from fourteen to thirty-three days. Dr. Girby's picture of a "carpet of writhing, newborn fleas, busily disporting themselves after their long entombment "in the egg cannot be accepted.

Correction.--In the article by Sir Sahib Singh Sokhey on "Therapeutic Substances in their International Aspects," which was published in last week's Journal, an incorrect reference was given under the heading of "Unification of Pharmacopoeias." It should have read " (Off. Rec. World Hlth Org., 10, 17)."

All communications with regard to editorial business should be addressed to THE EDITOR, BRITISH MEDICAL JOURNAL, B.M.A. HOUSE, TAVISTOCK SQUARE LONDON, W.C.1. TELEPHONE: EUSTON 2111. TELEGRAMS: Aitiology, Westcent, London. ORIGINAL ARTICLES AND LETTERS forwarded for publication are understood to be offered to the British Medical Journal alone. Authors desiring REPRINTS should communicate with the Publishing Manager B.M.A. House, Tavistock Square, W.C.1, on receipt of proofs.

B.M.A. House, Tavistock Square, W.C.1, on receipt of proofs. B M House Touls 9 a.m. to 5 p.m.) B.M.A. House, Tavistock Square, London, W.C.1 (hours 9 a.m. to 5 p.m.) MEMBERS' : SUBSCRIPTIONS should be sent to the SECRETARY of the Association. TELEPHONE: EUSTON 2111. TELEGRAMS: Medisecra, Westcent, London.

B.M.A. SCOTtish OfFice: 7, Drumsheugh Gardens, Edinburgh. 